The NHPs and OTCs met a "scientific test" when licensed by Health Canada, and manufacturers should be able to communicate that to consumers, Skinner says. "If you can provide the evidence that supports such a claim in a product that's appropriate for self-care, you should be allowed to do so."

Skinner also argues there's a public health benefit to such advertising. "If we are preventing people from being able to have access to products with labels that can describe what the product can be usefully used for, we're not doing the health system any favours whatsoever and it defies simple regulatory logic, let alone good science."

Skinner projects such advertising will be more in the vein of a trickle than a flood. "But if there are more products that are helping consumers to help themselves and keep them out of hospitals and so on, good."

Although Skinner dismisses the concern as unwarranted, Mintzes believes oversight of NHP and OTC advertising will be inadequate. She says a Health Canada review of non-Schedule A advertising of NHPs indicated that a majority of print ads and roughly onethird of broadcast ads presented inaccurate information.

But Health Canada says revised advertising guidelines (now in consultation phase) will establish that marketing claims must be consistent with evidence presented during a product's licensing stage.

"It has to be based on the Health Canada market authorization," says Ann Sztuke-Fournier, manager of Marketed Health Products Directorate's regulatory advertising and risk communications section.

"That's a roof built on a house of cards," Jeffery counters. "The adequacy of evidence accepted by Health Canada to approve health claims is so low the guidelines are doomed to fail public health."

Oversight of NHP and OTC advertising will continue to be vested with the not-for-profit industry body, Advertising Standards Canada, which will evaluate all ads before they can be shown to consumers. - Wayne Kondro, Ottawa

DOI:Io.I503/cmaj.060506

\section{Monitoring the price of new}

\section{drugs}

$\mathrm{T}$ he tribunal in charge of regulating drug prices in Canada should more closely scrutinize the price of new drugs, rather than the annual price increases posted by manufacturers on already-marketed drugs.

That message was delivered to the Patented Medicines Prices Review Board in response to a discussion paper on drug price increases released by the board in March 2005.

"They said we had the wrong description of the problem," explained PMPRB executive director Barbara Ouellet. As result, the board has produced a new discussion paper, scheduled to be posted on its Web site this spring.

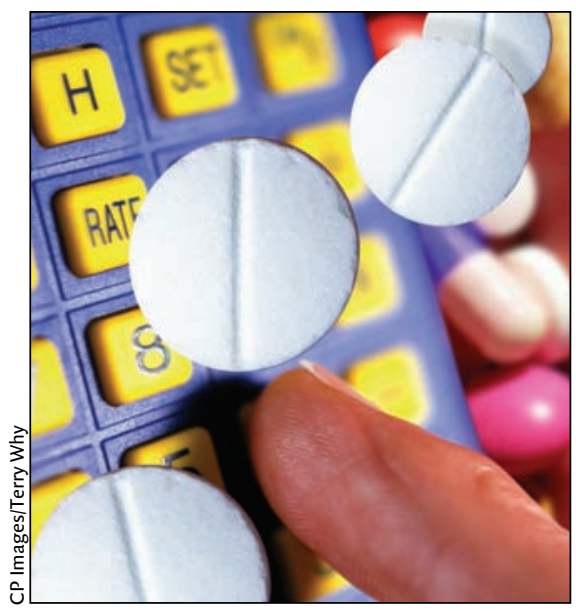

Pricing of generic drugs in Canada under review.

Last year's discussion paper was prompted by concern that in 2004 prices increased for $35 \%$ of all patented drugs, an unusually high percentage.

Manufacturers have the option of increasing prices according to a formula based on the Consumer Price Index, and need only inform the board at their next reporting period, which could be up to a year later. The discussion paper outlined alternative approaches, such as a requirement that companies apply in advance for and justify any price increases.

However respondents identified the introductory price of drugs as a key problem. A major driver behind increased retail spending on drugs is the substitution of newer, more expensive medications for older, less expensive ones, Dr. Joel Lexchin, associate professor of health policy at York University, noted in a submission to the board.

This substitution is achieved in large part by intense promotional activities, he wrote.

Insurer Green Shield Canada argued that the PMPRB should take into account spending on drug promotion (marketing and sales) in its initial pricing reviews, as well as spending on comparative trials that demonstrate the value of a drug compared to others in the same therapeutic class. (The board is now limited, under the Patent Act, in the factors it can consider in reviewing price.)

Manufacturers, on the other hand, have argued that because the board only recognizes 3 categories of drugs, which have different pricing considerations, companies are limited in their ability to charge more for improvements made to existing drugs. (The 3 categories are new dosages of existing drugs, "me too" drugs that offer little or moderate improvement over an existing drug, and breakthrough drugs.)

Green Shield also pointed to problems created by tiered pricing and a consequent lack of stability and transparency in pharmaceutical pricing. For example, a drug listed for \$I.9O on the Ontario Drug Benefit formulary in 2004 was sold to the Department of National Defence for 45 cents, it noted. As well, bulk buyers are sometimes offered rebates, and list prices are often higher than prices actually charged to larger pharmacy groups, the insurer noted.

Finally, some stakeholders argued that at the time of pricing of new patented drugs, the board should consider whether members of $R x \& D$, the association representing most trade name pharmaceutical companies in Canada, were meeting the commitment they made when they were granted patent extension to maintain a 10\% research and development to sales ratio in Canada. In 2004, this ratio dropped to $8.3 \%$ for all patentees, the lowest ratio seen since I989.

Meanwhile, this June the board will be posting the first quarterly report on pricing of generic drugs in Canada, Ouellet said. 
Last October, the federal, provincial and territorial ministers of health agreed to give the PMPRB "responsibility to monitor and report on non-patented drug prices." As well, to allow the board to regulate the price of non-patented drugs, "provinces will consider formally delegating their responsibility in this area to the federal government," the ministers stated in a press release. Ann Silversides, Toronto

DOI:I0.I503/cmaj.060505

\section{Pulse}

\section{Canada's future physicians:}

\section{Clinicians, researchers}

\section{or teachers?}

$\mathrm{A}$ lmost two-thirds of medical students who responded to the 2004 CFPC/CMA/RCPSC National Physician Survey said they hoped to include teaching in their future careers, and nearly one-third hoped to include research (Fig. I). The proportion of students who expressed an interest in these activities was greater than the proportion of practising physicians (family physicians and specialists combined) who actually participate in teaching and research. However, compared with specialists who participate in these activities, the proportion of students was lower. Nevertheless, the high level of interest among medical students in both research and teaching is encouraging, since these activities tend to have a negative impact on income.

Fig. 2 shows the breakdown of the students' preferences for their future career involvement by medical school. Students from the University of Western Ontario, the University of British Columbia and Dalhousie University were especially interested in both research and teaching, whereas those from Universite de Sherbrooke and the University of Saskatchewan were least interested. - Mark O. Baerlocher, Toronto

DOI:I0.I503/cmaj.051598

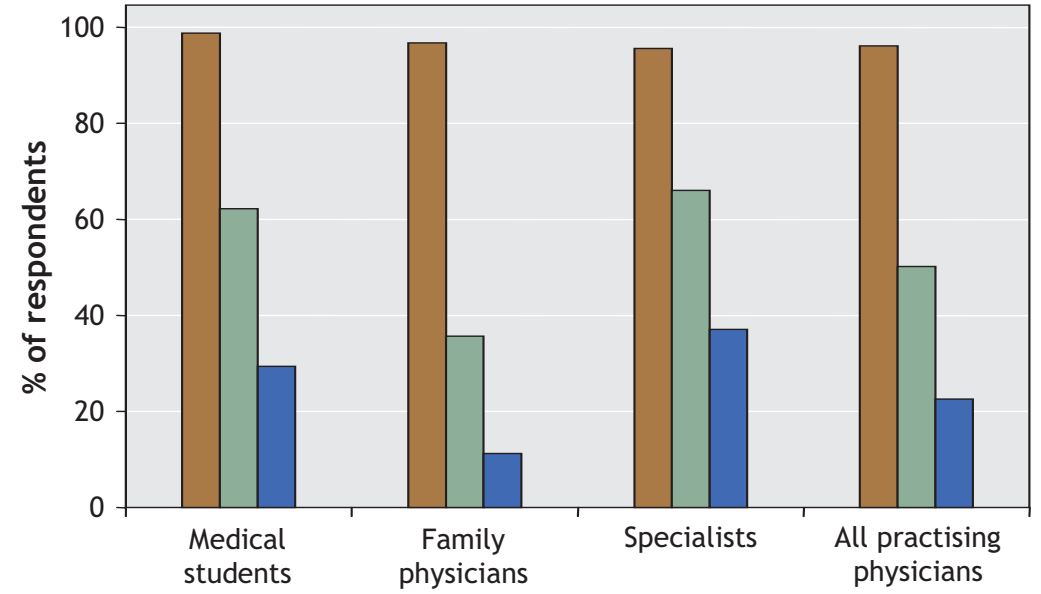

Patient care $\square$ Teaching $\square$ Research

Fig. 1: Proportion of medical students $(n=2688)$ who stated their plan to incorporate patient care, teaching and research into their future careers, compared with proportion of family physicians $(n=10632)$ and specialists $(n=9701)$ participating in those activities. Source: 2004 CFPC/CMA/RCPSC National Physician Survey.

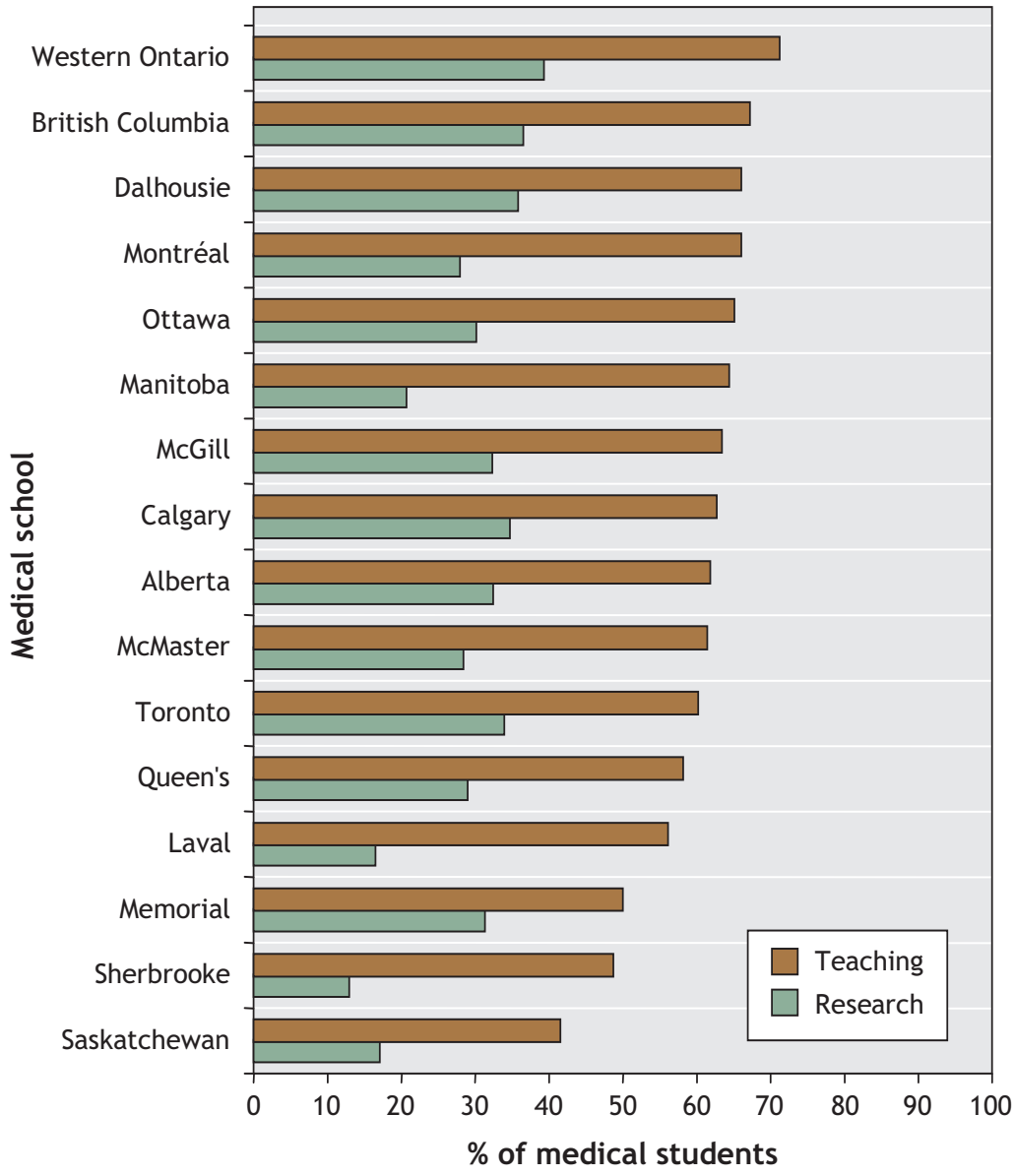

Fig. 2: Proportion of medical students $(n=2714)$ who stated their plan to incorporate research and teaching into their future practices, by medical school. Source: 2004 CFPC/CMA/RCPSC National Physician Survey. 